\title{
Comparison of analgesic efficacy of intramuscular tramadol and pethidine in labour
}

\author{
G. Vinaya, S. M. Surekha, Shivaganga Chiniwal*
}

Department of Obstetrics and Gynecology, Koppal Institute of Medical sciences, Koppal, Karnataka, India

Received: 02 August 2020

Accepted: 05 September 2020

\section{*Correspondence:}

Dr.Shivaganga Chiniwal

E-mail: gangu75@rediffmail.com

Copyright: () the author(s), publisher and licensee Medip Academy. This is an open-access article distributed under the terms of the Creative Commons Attribution Non-Commercial License, which permits unrestricted non-commercial use, distribution, and reproduction in any medium, provided the original work is properly cited.

\begin{abstract}
Background: Labour pain is among the most severe pain experienced by women. It is unpleasant and distressing to the parturient. The objective of the study was to evaluate and compare the analgesic efficacy and adverse effects of intramuscular tramadol and pethidine in labour.

Methods: The prospective study conducted in SDM College of Medical Sciences and Hospital, Department of OBG, from December 2013 to November 2014. The study was a study of the parturients admitted in the labour theatre. Written and informed consent was taken from all the patients enrolled in the study. One hundred parturient at term in active labour were randomly assigned to one of the two groups to receive intramuscularly either tramadol 100 mg or pethidine $75 \mathrm{mg}$.

Results: Results were comparable in terms of maternal age, maternal weight and neonatal weight. Proportion of cases with satisfactory to good pain relief was $74 \%$ in the tramadol group and $78 \%$ in the pethidine group. Nausea and/or vomiting (12\% versus $8 \%)$, fatigue $(6 \%$ versus $4 \%)$ and drowsiness $(8 \%$ versus $4 \%)$ were significantly high in the pethidine group than the tramadol group $(\mathrm{p}<0.05)$. The drugs used did not appear to influence the mode of delivery. Proportion of cases with non-reassuring foetal heart rate was high in the pethidine group. Meconium stained liquor was equally seen in both the groups and there were no incidence of neonatal respiratory depression in any of the groups.

Conclusion: Tramadol is an equally effective labour analgesic as pethidine with less maternal and perinatal side effects.
\end{abstract}

Keywords: Labour analgesia, Primigravidae, Tramadol, Pethidine

\section{INTRODUCTION}

The intensity of labour pain experienced during labour affects maternal psychology, labour progress and foetal well-being. For this reason, one of the basic principles of modern obstetrics is to provide adequate analgesia. The need for analgesia to overcome pain in labour is highly requested by women today. There is no other circumstance in which it is considered acceptable for a person to experience untreated severe pain, amenable to safe intervention, while under a physician's care. In the absence of a medical contraindication, maternal request is sufficient medical indication for pain relief during labour. ${ }^{1}$
Pain and agony during child-birth is quite unbearable and at times beyond description. Labour pain is a result of many complex interactions, physiological and psychological, excitatory as well as inhibitory. The pain if not adequately controlled may affect respiratory, cardiovascular, gastrointestinal, urinary and neuroendocrine functions due to segmental and supra segmental reflexes. Pain also reduces uteroplacental blood flow leading to altered foetal homeostasis. ${ }^{2}$ Labour can be both physically and psychologically stressful for women and the resulting detrimental effects on the foetus are well documented. ${ }^{3}$ 
The relief of pain during childbirth and provision of dignified birth experience has been of great interest both to the obstetrician and anaesthesiologist. Adequate analgesia during labour is of benefit to the mother and has a positive influence on the course of labour and the state of newborn child, thus making obstetric analgesia an essential part of modern obstetrics. ${ }^{4}$

Effective analgesia during labour will prevent these avoidable consequences. Various ways either nonpharmacologic example, emotional sustain, psycoprophylactic preparation, yoga and hypnosis or pharmacologic such as epidural blockade or parenteral opioid analgesics are used. ${ }^{5}$

There are many drugs and methods used for labour analgesia. An ideal analgesic technique used should be cheap, easy to administer, produce good and reliable pain relief but not impair consciousness or cooperation. It should not be toxic to mother and foetus and not produce cardio-respiratory depression in the foetus. The technique must not have any tocolytic action and not delay the labour. $^{6}$

Thus, there is a need for a safe and effective analgesic with minimal maternal and foetal side effects. In addition, it should be very simple to administer. Epidural analgesia has been popularly used for pain relief in western countries for nearly three decades. In India, its use is limited due to lack of awareness, trained staff and monitoring facilities and injectable opioids such as meperidine (pethidine) and tramadol are reasonably used. In developing nations where availability of resources is the main limiting factor, intramuscular opioids are the choice. ${ }^{7}$

Tramadol is one such weak opioid analgesic with analogous analgesic efficacy to pethidine, less maternal sedative effect and less neonatal respiratory depression. ${ }^{8}$

Therefore, the present prospective comparative study was done to compare the analgesic efficacy, tramadol with pethidine (meperidine) in active labour, both of which are used for pain relief in labour.

\section{METHODS}

The prospective study conducted in SDM College of Medical Sciences and Hospital, Department of OBG, from December 2013 to November 2014. The study was a study of one hundred primigravid women presenting with full term pregnancy admitted in the labour theatre. Written and informed consent was taken from all the patients enrolled in the study. The study was approved by the institutional ethical committee.

\section{Inclusion criteria}

All primigravid women presenting with full term pregnancy singleton pregnancy vertex presentation. In active phase of labour active phase of labour is defined as cervical dilatation more than $4 \mathrm{~cm}$ cervix $70 \%$ to $80 \%$ effaced good uterine contractions i.e., 3 contractions lasting for 45 seconds in 10 minutes.

\section{Exclusion criteria}

Patients were excluded from the study if they had: parturients with associated obstetrical complications, multiple gestation, anti-partum hemorrhage, hypertensive disorders of pregnancy, intrauterine fetal growth restriction, cephalopelvic disproportion, etc., any associated history of medical disorders, diabetes, hypertension, epilepsy, liver disorder and psychiatric disorders and any history of hypersensitivity to the drug under study.

Written and informed consent was taken from all the patients enrolled in the study. They were evaluated by history taking, clinical examination and investigations. One hundred parturients at term in active phase of labour were randomly assigned to one of the two groups to receive intramuscularly either tramadol $100 \mathrm{mg}$ or pethidine $75 \mathrm{mg}$. Patient was instructed to inform as soon as pain begins to decrease in intensity or even if there is no pain relief at all. Single person who was not aware of the given drug assessed the analgesic effect using Visual analogue scale (VAS). Pulse rate, respiratory rate, blood pressure, FHR were recorded. Partogram was recorded to assess the progress of labour. Maternal side effects, effect on labour, and perinatal outcomes were studied.

The following observations were recorded and compared within the two groups.

- Onset of action of the drug.

- Drug side effects change in vital parameters at first every 30 minutes for two hours and then hourly for two hours were monitored.

- Foetal heart rate monitoring was done clinically and any variability noted.

- Progress of labour was monitored clinically.

- Assessment of analgesia was done after two hours and four hours of giving the drug by scoring system, degree of pain relief noted.

- Patient level of consciousness, alertness was judged.

- The duration of labour.

- The mode of delivery.

- Birth weight of the neonate.

- Apgar score at 1 minute and 5 minutes interval after delivery of the neonate.

- Any complications during the course of labour were recorded.

\section{Assessment of pain relief}

The degree of pain relief was assessed using the visual analogue scale. It is almost impossible to comprehend the degree of pain and agony women endure during delivery. It is a challenge to measure pain. Various methods exist 
but none can guarantee pain measurement conclusively. 9 During the course of our study pain relief was analyzed and recorded using visual analogue scale after administration of the drug.

The degree of pain relief was graded as shown below.

- Grade I- Good pain relief

- Grade II- Satisfactory pain relief

- Grade III- Mild pain relief

- Grade IV- No/poor pain relief

\section{Statistical analysis}

Effect of the drugs used on maternal and fetal wellbeing was compared within the study groups. The quantitative analysis was done using unpaired t-test and for qualitative analysis chi-square test was applied.

\section{RESULTS}

In this study, 100 primigravidae patients of different age group in labour were studied to evaluate the efficacy and safety of tramadol hydrochloride in comparison with pethidine in providing pain relief during labour.

From the table, in the tramadol group maximum of $78 \%$ are in the age group of $19-25$ years and $16 \%$ in the age group of 26-30 years. About 6\% are in the age group of 31-35 years. Minimum age of women in the tramadol group was 19 years and maximum age 32 years. The mean age of women was 23.58 years with a standard deviation 3.189 .

From the table, in the pethidine group maximum of $80 \%$ are in the age group of 19-25 years and 14\% in the age group of 26-30 years. About 6\% are in the age group of 31-35 years.

Minimum age of women in the pethidine group was 19 years and maximum age 34 years. The mean age of women was 23.08 years with a standard deviation 3.416 .

In the tramadol group two hours after the administration of the tramadol 32 women $(64 \%)$ had satisfactory pain relief, 5 women (10\%) had good pain relief and 13 women (26\%) had mild pain relief (Table 1).

Table 1: Degree of pain relief in labour in Tramadol group.

\begin{tabular}{|lll|}
\hline Degree of pain relief & N & Percentage \\
\hline Good (grade I) & 5 & 10 \\
\hline Satisfactory (grade II) & 32 & 64 \\
\hline Mild (grade III) & 13 & 26 \\
\hline No/poor (grade IV) & 0 & 0 \\
\hline Total & 50 & 100 \\
\hline
\end{tabular}

In the pethidine group two hours after the administration of the pethidine 30 women $(60 \%)$ had satisfactory pain relief, 9 women (18\%) had good pain relief and 11 women $(22 \%)$ had good pain relief (Table 2 ).

Table 2: Degree of pain relief in labour in Pethidine group.

\begin{tabular}{|lll|}
\hline Degree of pain relief & N & Percentage \\
\hline Good (grade I) & 9 & $18 \%$ \\
\hline Satisfactory (grade II) & 30 & $60 \%$ \\
\hline Mild (grade III) & 11 & $22 \%$ \\
\hline No/poor (grade IV) & 0 & 0 \\
\hline Total & 50 & $100 \%$ \\
\hline
\end{tabular}

Table 3: Effect on outcome of labour in Tramadol group.

\begin{tabular}{|lll|}
\hline Labour characteristic & $\mathbf{N}$ & Percentage \\
\hline Normal vaginal delivery & 36 & 72 \\
\hline $\begin{array}{l}\text { Instrumental vaginal } \\
\text { delivery }\end{array}$ & 6 & 12 \\
\hline Caesarean delivery & 8 & 16 \\
\hline $\begin{array}{l}\text { Vaginal delivery within } 4 \\
\text { hours }\end{array}$ & 35 & 70 \\
\hline Total & 50 & 100 \\
\hline
\end{tabular}

In the tramadol group 32 women $(72 \%)$ normal vaginal delivery, 6 women $(12 \%)$ had instrumental vaginal delivery and 8 women (16\%) delivered by caesarean section. Table 3

In the pethidine group 34 women $(68 \%)$ had normal vaginal delivery, 7 women $(14 \%)$ had instrumental vaginal delivery and 9 women $(18 \%)$ delivered by caesarean section. Table 4

Table 4: Effect on outcome of labour in pethidine group.

\begin{tabular}{|lll|}
\hline Labour characteristic & $\mathbf{N}$ & Percentage \\
\hline Normal vaginal delivery & 34 & 68 \\
\hline Instrumental vaginal delivery & 7 & 14 \\
\hline Cesarean delivery & 9 & 18 \\
\hline $\begin{array}{l}\text { Vaginal delivery within 4 } \\
\text { hours }\end{array}$ & 38 & 76 \\
\hline Total & 5 & 100 \\
\hline
\end{tabular}

The drugs used did not appear to influence either the observed duration or mode of delivery. Number of women with vaginal delivery was higher in group receiving tramadol than pethidine but not statistically significant. Both groups had almost similar instrumental vaginal and caesarean delivery. The mean duration of labour was shorter in the pethidine group and also the number of women delivering within 4 hours was higher. 
Table 5: Degree of pain relief in labour in study groups.

\begin{tabular}{|lllllll|}
\hline $\begin{array}{l}\text { Pain relief /evaluated } \\
\text { time }\end{array}$ & \multicolumn{3}{l}{ Tramadol $(\mathbf{n = 5 0}$} & \multicolumn{5}{l|}{ Pethidine $(\mathbf{n}=\mathbf{5 0})$} \\
\hline Good (grade I) & 00 & $2 \mathrm{~h}$ & $4 \mathrm{~h}$ & 0 & $2 \mathrm{~h}$ & $4 \mathrm{~h}$ \\
\hline Satisfactory (grade II) & 00 & $05(10)$ & 00 & 0 & $9(18)$ & 00 \\
\hline Mild (grade III) & 00 & $13(64)$ & $06(12)$ & 0 & $30(60)$ & $8(16)$ \\
\hline No/poor (grade IV) & 50 & 00 & $09(18)$ & 0 & $11(22)$ & $4(8)$ \\
\hline Total & 50 & 50 & 00 & 50 & 00 & 00 \\
\hline
\end{tabular}

*35 women delivered within 4 hours in tramadol group, \#38 women delivered within 4 hours in pethidine group.

The pre analgesic median visual analogue score of perception of pain was grade IV in both the groups. The calculated median pain perception scores did not show significant difference between the groups with change in time. Based on pain perception score satisfaction level was calculated. Since the maximum analgesic action of single dose of these drugs is up to 2 hours and wanes off by 4 hours, only the results at these hours are studied. Number of women recording good to satisfactory pain relief was higher in the pethidine group. The average visual analogue scores and the number of women in each satisfaction levels remained similar (Table 5).

\section{DISCUSSION}

Pain is the most important human experience and also is most complex. Pain experienced during labour is reported as severe or intolerable in up to $61 \%$ of women who went through labour. This discomfort may result in harmful physiologic responses in both the mother and foetus. In addition, pain during childbirth may result in the experience being distressing and disappointing for the parturient. $^{10}$

In a scholarly review Lowe in 2002 emphasized that the experience of labour pain is a highly individual reflection of variable stimuli that are uniquely received and interpreted by each woman indivisually. ${ }^{11}$

The American College Of Obstetrics and Gynecology in 2002 reaffirmed its position published jointly with the American Society of Anesthesiologists, that a request for pain relief by the woman is sufficient medical indication for its use.

Tramadol is as effective as pethidine in the treatment of labour pain and is cheaper than it. It may be preferred over pethidine as it is associated with less sedation and cause less neonatal respiratory depression. The onset of analgesic effect is faster (within 10 minutes) after subcutaneous or intramuscular administration, and the effect reaches a peak in one hour that corresponds closely to peak concentration in plasma. In clinical use the duration of effective analgesia is 1.5 to 3 hours. In general, 75 to $100 \mathrm{mg}$ of pethidine given intramuscular (IM) is approximately equivalent to $10 \mathrm{mg}$ of morphine. ${ }^{12}$

Both the groups had no/poor pain relief before administering the drug. After two hours of giving the drug in the pethidine group $18 \%$ had good pain relief, $60 \%$ had satisfactory pain relief and $22 \%$ had mild pain relief. In the tramadol group, two hours after drug administration $10 \%$ had good pain relief, $64 \%$ had satisfactory pain relief and $26 \%$ had mild pain relief. In the pethidine group after four hours of drug administration barring the women who delivered within four hours, none had good pain relief, 8 women $(16 \%)$ had satisfactory pain relief and 4 women $(8 \%)$ had mild pain relief. In the tramadol group after four hours of drug administration excluding the women who delivered within four hours, none had good pain relief, 6 women $(12 \%)$ had satisfactory pain relief and 9 women (18\%) had mild pain relief.

The calculated median pain perception scores did not show significant change between the two groups with change in time. These results are comparable to earlier studies where the analgesic effect of tramadol was equal to pethidine but with a superior safety profile. Fieni et al in 2000, obtained similar results. They evaluated the efficacy and tolerability of the two opioids usually used today in parenteral analgesia to reduce pain during labour: tramadol and pethidine. In their study a moderate maternal analgesic effect was demonstrated in both the groups. They concluded that tramadol gave an analogous analgesic effect, with better tolerability for the absence of collateral effects on the mother, foetus and the newborn. ${ }^{13}$

\section{CONCLUSION}

Tramadol hydrochloride is an effective and safe labour analgesic, producing satisfactory analgesia when compared to pethidine. In addition, it does not affect the course of labour. Hence it can be concluded that, tramadol hydrochloride is an equally effective labour analgesic as pethidine.

\section{ACKNOWLEDGMENTS}

I would like to express my profound gratitude to all the participants for their co-operation and for their immense faith they reposed in me.

Funding: No funding sources

Conflict of interest: None declared

Ethical approval: The study was approved by the Institutional Ethics Committee 


\section{REFERENCES}

1. American College of Obstetrics and Gynecology. ACOG practice bulletin. Obstetric analgesia and anesthesia. Number 36, July 2002. American College of Obstetrics and Gynecology. Int J Gynaecol Obstet. 2002;78(3):321-35.

2. Nagaria T, Acharya J. J Obstet Gynecol India. 2006, 56: 406409.

3. Horsager R, Roberts S, Rogers V, Santiago-Munoz, Worley K, Hoffman B. Normal Labour. In: Williums Obstetrics 24th edition. McGrawHill Education. 2014.

4. Veigus OA. Tramadol in labour pain in primiparous patients-A prospective comparative clinical trial. E.J. Obst \& Gynec \& Reprod Biology. 1993;49:131-5.

5. Fieni S, Angeri F, Kaihura CT. Perinatal effects of 2 analgesics, Tramadol chlorhydrate and Mepiridine chlorhydrate, when used during labour. Acta Biomed Ateneo Permense. 2000;(71)1:397-400.

6. Keskin HL, Aktepe Keskin. Pethidine versus tramadol for pain relief during labour. International J Gynecol Obstet. 2003;82(1):11-6.

7. Jain. Analgesic efficacy of intramuscular opioids versus epidural analgesia in labour. Int J Gynecol \& Obstet. 2003;83(1):19-27.
8. Fieni S, Angeri F, Kaihura CT. Perinatal effects of 2 analgesics, Tramadol chlorhydrate and Mepiridine chlorhydrate, when used during labour. Acta Biomed Ateneo Permense. 2000;(71)1:397-400.

9. Heever HT, Keela CA. Method of testing analgesia in man. Lancet. 1948;1:683.

10. Ward ME. Acute pain and the obstetric patient: Recent developments in analgesia for labor and delivery. In: Molloy AR, Poer I (editors). Acute and chronic pain. International Anesthesiology Clinics, USA. Lippincott Raven. 1997;83-8.

11. Williams Obstetrics, 24th Edition. Normal labour, Obstetric Analgesia \& Anaesthesia; chapter 24

12. Brunton L, Chabner BA, Knollman B. Goodman \& Gilman's The Pharmacological Basis of Therapeutics, Section III, Drugs acting on the CNS, $12^{\text {th }}$ edition. 2011: 360-373.

13. Feini S, Angeri CT, Kaihura. Evaluation of peripartum effects of 2 analgesics- mepiridine and tramadol used in labour. Acta Biomedl Ateno Permense. 2000;(71):397-400.

Cite this article as: Vinay G, Surekha SM, Chiniwal S. Comparison of analgesic efficacy of intramuscular tramadol and pethidine in labour. Int J Reprod Contracept Obstet Gynecol 2020;9:4197-201. 